\title{
Teachers' Personal Theories of Teaching: Managing Cultural Diversity in Mainstream Public Primary Schools in Greece
}

\author{
Vassiliki Papadopoulou \\ University of Western Macedonia, Greece \\ Kyriaki Theodosiadou \\ University of Western Macedonia, Greece \\ Nektaria Palaiologou ${ }^{1}$ \\ Hellenic Open University, Greece
}

\begin{abstract}
The phenomenon of migration has transformed the Greek school into a multiethnic environment, reshaping the issues raised about good practices and the role the teacher plays in the smooth integration of diverse cultures, not only in the school but also in the wider Greek society. This paper examines how cultural diversity is managed in Greek primary schools by focusing on the content of teachers' personal theories, which guide their actions, although those actions to a large extent show lack of consciousness. The study investigated the personal theories of five female primary school teachers in the Regional Unit of Pella in Central Macedonia, Greece, using qualitative research methods, through a variety of tools, such as teaching observation, in-depth interviews, and text analysis. These teachers, although teaching in mainstream schools, have students from other ethnic backgrounds in their classes. The findings show that teachers' personal theories on which they base how they manage cultural diversity are largely still determined by an assimilative approach.
\end{abstract}

Keywords: Cultural diversity, Greece, intercultural education, personal theory.

\section{Introduction}

Emigration has been a dominant factor in the history of the Greek nation. However, within the last thirty years the phenomenon of immigration has emerged, with immigrants today accounting for approximately 10\% of the population (Bolkas, 2015; Palaiologou, 2020; Rakkas, 2017). Consequently, there has been a significant increase in the presence of students from diverse minority (ethnic, racial, linguistic and/or religious) backgrounds in Greek schools (Govaris \& Kaldi 2010; Palaiologou et al., 2019; Palaiologou et al., 2020), which has transformed the composition of the student population from homogeneous to multicultural. This cultural diversity in Greek schools means that educators and the education system are faced with a set of novel, challenging and compelling issues (Tsaliki, 2012), of which the most important is the smooth integration of migrant students into the wider Greek society (Palaiologou, 2013). It is essential that both the school as a social institution, and teachers as the primary agents in the educational process ensure that inclusion in school focuses on the recognition and acceptance of the diverse "ethno-cultural capital" of the migrant children (and

\footnotetext{
${ }^{1}$ Corresponding Author E-mail: nekpalaiologou@uowm.gr
} 
more recently refugee children), as well as on the principles of equality of educational opportunities to establish social justice, social cohesion and strengthen their multiple identities (Banks, 2006; Cummins in: Schmidt 2015; Gurer, 2019; Kaldi et al., 2017; Ratini, 2019).

\section{Challenges in the Educational Setting}

The phenomenon of immigration which Greece has faced over the last 30 years has had the effect of radically transforming contemporary Greek classrooms into multicultural ones (Gropas \& Triandafyllidou, 2011; Govaris, 2011; Nikolaou, 2011; Palaiologou, 2013). This has clearly demonstrated to educators, and to society more widely, that a mono-cultural and narrowly nationally-oriented educational system is obsolete as it no longer responds to the reality of the 21 st century (Dietrich, 2006). The imperative for an intercultural educational framework has been brought to the forefront of educational and social and policy since the mid1990s.

A culturally diverse classroom has also presented challenges to teachers (Hysa, 2020), related to the fact that migrant students face social and learning difficulties because they do not have adequate command of the Greek language. They find it hard not only to follow the academic program, but also to communicate and develop social relationships in their class, and generally in the school environment (Cummins in: Schmidt 2015; Inglis, 2008; Palaiologou \& Evangelou, 2012; Papadopoulou, 2008). Another major set of challenges accompanying the education of diverse groups is the implementation of the principles of intercultural education, where the cultural capital of these children must first and foremost be respected, and the school finds ways of applying it (Hajisoteriou \& Angelides, 2016).

Although theoretically has been emerged the need for school's intercultural orientation, educational practice shows that the current Greek educational system still underestimates the cultural diversity of migrant students (Govaris 2011; Nikolaou 2011; Palaiologou \& Evangelou, 2012). This has been highlighted by relevant research (Gropas \& Triandafyllidou, 2011; Kaldi et al., 2017; Karanikola, 2015; Palaiologou \& Faas, 2012; Sakka, 2010), which also reveals that the Greek educational system has characteristics of assimilationism. Teachers themselves need to make a concerted effort to adapt to the multiethnic composition of their classes; they need to review many of their embedded assumptions and question their role as representatives of the dominant culture (Sharan, 2010). This emphasizes the permanent need for the intercultural educational training of teachers in order for them to be able to effectively respond to the challenges posed by multiculturality. In addition, they will be able to successfully manage the diversity of cultures in their classrooms (Beckett \& Kobayashi, 2020; Ciges \& Lopez, 1998; Domingo \& Guerrero, 2018; Gibbs, 2020; Karanikola, 2015; Kesidou \& Papadopoulou, 2008; Magos, 2007; Palaiologou, 2004), notwithstanding the institutionalized efforts that have been made in the last two decades by the state and by European large-scale programs.

\section{The Meaning and Importance of the Study of Personal Theories and Related Research on the Management of Cultural Diversity}

The perceptions and experiences of the individual influence the way they understand and interpret the world around them (Richardson, 1996; Yusoff, 2019). In this research project our theoretical framework for conceptualizing perceptions, views, beliefs and experiences of teachers is the concept of the personal theory, most well-known and used in the German speaking academic space as «Subjektive Theorien», established through the research project "Forschungsprogramm Subjektive Theorien. Eine Einführung in die Psychologie des reflexiven Subjekts" (Research project subjective theories: An introduction to the psychology of the reflective subject) conducted by the group of Norbert Groeben, Diethelm Wahl, Jörg Schlee und Brigitte Scheele and published 1988 with this title. 
Personal theories (subjektive theorien) refer to the self and to the world. Theyare constituted "from aggregates of basically updatable cognitions in which the subjective view of experiencing and acting are reflected upon" (Mandl \& Huber, 1983, p. 98). Therefore, personal theories contain not only assumptions about how we think and feel and how we act, but also interpretive "lenses" concerning our own behavior and that of other people (Scheele \& Groeben, 1998). According to Scheele \& Groeben (1988) there are four main features characterizing a personal theory: a) they represent a system of relatively stable cognitions, b) they are mostly implicit, but they can be articulated by providing guided support, c) like scientific theories they have an argument structure, so they can be used to explain and to predict actions as they include if-then relationships, d) by having such an argument structure they fulfill functions such as the defining of a situation, the explaining of events and interactions, the predicting of future actions and reactions, and the generating of plans and recommendations. Personal theories furthermore have the potential to guide our actions and reactions both in everyday life and in the field of our professional practice (Dann, 1989). It should be noted that personal theories within the framework of this epistemological concept (Sousa 2014) can be "revealed" and reconstructed through the dialogue consensus method (Groeben \& Wahl, p. 33). This was the methodological line we followed in our research.

Research on personal theories of teachers has investigated the relationship between professional knowledge or personal theories and action in school settings from a range of perspectives (Bromme, 1980; Calderhead, 1996; Dann, 1989; Dann et al., 1987; Richardson, 1996; Straub \& Weidemann, 2015; Tarman \& Tarman, 2011). The importance of studying teachers' personal theories lies in the fact that in routine situations one tends to act without being aware of the cognitive processes that guide one's actions, which happens only when having to deal with a problem or critical situation. Therefore, it is crucial for the teachers to understand and to reflect on the personal theories which guide their actions. This process not only helps them in self-improvement but also enables them to deal with problematic situations in the classroom setting with more knowledge and self-confidence (Burkett, 2014; Dann, 1989; Dann, 1994; Ferris, 2019; Mandl \& Huber, 1983; Theodosiadou \& Papadopoulou, 2015).

As has already been underlined, the concept of personal theory originates from the German speaking space; its equivalent in others settings and research projects can be seen in the concepts of beliefs, views or attitudes (Fussangel, 2008, p. 71). A number of researchers have been involved in the study of teachers' views and attitudes on the management of issues related to intercultural education and the inclusion of immigrant students. A large-scale survey by Kaldi et al. (2017) found that Greek primary school teachers view diversity more as a challenge than a barrier to the teaching/learning process, and recognize the need for differentiated instruction in their attempts to manage cultural diversity in their classrooms. In contrast, an empirical study by Gropas and Triandafyllidou (2011) showed that in the Greek educational system, there is a widespread perception that Greek and migrant students should be treated in exactly the same way regardless of the parents' legal status. It also shows that the intercultural dimension is neither a priority nor a necessary part of more general educational reform, while attempts at inclusion of the migrant student population are carried out in terms of an implicit assimilative approach. Assimilative tendencies in Greek schools were also indicated by the two separate studies referred to by Palaiologou \& Faas (2012). The findings of these studies revealed that any cultural and religious diversity, which is treated as a problem, is excluded from educational practice and emphasis is placed on learning the Greek language and culture, ignoring the language and culture of migrant students (Skourtou et al., 2020). Similarly, a study by Sakka (2010) showed that teachers strongly believed that migrant students should only use the Greek language at school. Hence, they felt that it was problematic when they spoke their mother tongue, which they believed should be corrected through linguistic assimilation into the dominant language of the host countries. Moreover, a study by Pantazi (2008) about 
Bilingual Pedagogy and Teachers' Theories in the Greek Community Schools showed that teachers' theories are dynamic, and develop in a broadly reflective manner. The teachers informally 'research' problems they encounter in the language classroom, developing a rich local knowledge of the students (including the form of diglossia in the community, students' learning styles, forms of motivation, etc.). Their reflections feed into practice as their teaching methods become more closely tailored to the needs of their students.

\section{Research}

Aim

The present research is a pilot study whose aims were to explore the personal theories of primary school teachers who teach in mainstream schools and have students from other ethnic backgrounds in their classes, in order to examine how they think and how they manage cultural diversity in the classroom.

\section{Participants, Setting}

This pilot study was based on a purposive (non-random) sample of five (5) female primary school teachers who agreed to participate in the research. The reason that the sample was only women is due to the fact that most teachers in Greece are female. They were from two (2) mainstream government public schools in the Municipality of Skydra in the Regional Unit of Pella in Central Macedonia, Greece, and their length of service ranged from six (6) to twentytwo (22) years. One school was in a small rural town (3 teachers), while the other was in a neighboring village ( 2 teachers). The teachers taught in first, fifth and sixth grade, i.e. 6-7 years old for the first grade, 9-10 years old for the fifth and 10-11 years old for the last-sixth grade.

The rationale for the choice of the location of schools for the pilot study was that the area is relatively far from large urban centers, where there is a possibility for more exchange between teachers at a theoretical and practical level, which could influence their personal theories. A wider selection of schools and locations are included in the forthcoming main study. In addition, it was assumed that the school in the town would have a larger student population per class in comparison to the village school, which might also play some role in teachers' attitudes and behavior concerning intercultural education. The number of migrant students ranged from one (1) to five (5) per class, the majority of whom had their origins in Albania and then from the former Soviet Union.

Although non-random samples have specific limitations, mainly that the target population is hard to identify, it was not a limitation in the present pilot study as generalization of results was not intended due to the small sample size. However, the study has internal validity, and the results have provided important information for further consideration in the forthcoming main study.

\section{Method}

The research methodology used was introspection ${ }^{2}$, a combination of methods discussed below. Introspection has been widely applied in the field of psychology and involves "the perception of one's internal, psychological processes, in this case, the primary school teachers" (Scheele \& Groeben, 1998, Theodorou, 2012), which form their personal theories. Specifically, in order to reconstruct and study each teacher's personal theory a combination of two research

\footnotetext{
${ }^{2}$ In German: Introspektion, developed by German psychologist Wilhelm Wundt (1832-1920) (cited in Danziger 2001).
} 
tools was used. The first one was that of subsequent thinking, using the think-aloud technique , $^{3}$ applied mainly in psychological research to examine the relationship between thought and action (Scheele \& Groeben, 1998). The other tool was stimulated recall, which enables cognitive processes to be investigated by helping participants to remember their concurrent thinking (Calderhead, 1981; Wahl, 1981). In order to triangulate the research methodology, we used classroom observation. This method enables the researcher to pick up nonverbal expressions of feelings and attitudes, to see interactions taking place, grasp the communication processes in the field, as well as check on the amount of time that is spent by the participant/teacher on each activity and with a group of students (Papadopoulou, 2015). The research was divided into four stages in which these methods were used.

\section{Data Collection}

In the study preparation phase, we informed the teachers about the aims and the research method. The process of data collection was the tape recording of each teacher's lessons. The teaching hours that were tape recorded did not exceed a total of 9 hours in two consecutive days on a variety of subjects covered in the elementary school curriculum.

As noted, another tool for data collection was classroom observation: it was unstructured, since our aim was to sort the observational data into general categories, which in the next phase of the study would be more specialized.

From the recordings of the teaching we prepared the stage of think-aloud and stimulated recall, since the interview/discussion with the teachers was based on listening to the recording of the teaching and their trying to recall thoughts which they had had during the lesson. At this stage a discussion with each teacher on the recorded teaching was held, lasting on average for 2 hours. In a semi-formal personal interview/dialogue, with only a few predetermined questions (for the interviewer to be open and adaptable to the participant's attitudes and responses), the teachers were asked to express their thoughts on the points of instruction related to the management of cultural diversity. The next step was to go deeper into the dialogue. At this stage, there was discussion on issues that emerged from the previous dialogue, which served to fill any existing gaps found in the processing phase.

\section{Data Analysis}

Based on the collected data we attempted to reconstruct the teachers' personal theories, which, however, were finalized after the dialogue-consensus phase (see below). We formulated theories in the manner of: 'if ... then ...'. For example, based on the teacher's statement: "When [the migrant student] had first come, he was afraid, he did not speak Greek, and I treated him well. I spoke to him as I would speak to a Greek stude", we formulated the hypothesis: "If you treat a migrant student like a Greek student, then does that mean that you treat them well?"

During the dialogue-consensus phase ${ }^{4}$, in a last stage for the teachers, they were given a questionnaire, which included three columns: the first included the personal theories we had formulated from their statements, the second was for the teacher to indicate whether they agreed (A) or disagreed (D) that they held that theory, and the third was to add comments if they wished to do so on the theory.

Next, we went through the formation of a general and integrated personal theory for each teacher, using qualitative content analysis (Mayring, 2000). This method was considered to be the most appropriate for the categorization of the teachers' personal theories, because,

\footnotetext{
${ }^{3}$ In German: «lautes» Denken (Scheele \& Groeben, 1998).

${ }^{4}$ In German: Dialog-Konsens-Methoden (Theodorou, 2012, p. 65).
} 
after collecting all the necessary data, it was put into particular categories, which were then interpreted. Based on the final material, three main categories were developed: The Didactical Process, the Pedagogical Process and Management of Cultural Diversity. In this paper, we present the results and discussion of the third category, Management of Cultural Diversity.

Regarding the data of the observation, we collected 26 narrative protocols from 42 teaching hours. The analysis of the data was based on the categories that emerged and which are analyzed below. The purpose of this analysis was to confirm or refute what teachers claimed regarding the management of ethnocultural diversity. For reasons of economy, the results are not analyzed in the present work, however, it is worth mentioning some of its key findings. Teachers do not differentiate teaching due to the multicultural composition of their classroom. Greek and migrant pupils are treated in the same way, which was evident from the fact that they were given equal opportunities to participate in the lesson and were rewarded or punished the same. However, while the teachers spoke of respect for the cultural diversity of migrant pupils from their and the Greek pupils part, in reality it seemed that it was ignorance or indifference to immigrants' cultural characteristics, since they are not taken into account in everyday teaching practice, while in several cases Greek pupils did not seem to know the different cultural identities of their immigrant classmates.

\section{Research Findings}

\section{The Teacher's Role in Managing Cultural Diversity}

Regarding the role of the teacher in the management of cultural diversity in the classroom, theories were formed regarding differentiated instruction and the approach to assessing school performance when the composition of the class is multicultural.

The findings showed that teachers did not implement differentiated teaching when the composition of their class was multicultural, but limited themselves to expressing theories about how, in their view, the teacher should manage such a classroom setting. They thus made reference to the fact that teaching a multiethnic class differs from a homogeneous one. They believed that the differences lie in discussions on racism that may arise and that the teacher should not hesitate to refer to issues of diversity and to speak openly about them. At the same time, however, it was stated that the teacher must ensure that in a multicultural classroom such discussions are made with greater sensitivity and respect from all sides:

Do you know where I have to differentiate it? When we talk about
racism, etc. Now, in one of the text books, we came across something
about the gypsies, immediately the children began to say that the
gypsies that went to the playground dirtied it, and that they often
stole things. (R3)

Some views expressed by the teachers concerned what their role ought to be when the composition of the class is multicultural. Thus, it was stated that the teacher can help all migrant children improve their school performance level:

I raised the level of my migrant students. That is, I gave them more attention. I gave them differentiated teaching. I saw where they were having difficulty, and I slowly made them catch up with the other children. (R2)

It was also reported that the teacher must differentiate their instruction whenever deemed necessary, for example to vary the wording of the questions according to the student 
being addressed and to check the level of each student individually, which does not always have to do with the student's ethno-cultural origins:

Teaching is always differentiated, not in relation to nationality, but in relation to the child's weaknesses wherever they come from. (R3)

Lastly, it was reported that the teacher cannot have the same expectations with respect to all students, no matter if they are Greeks or migrants, and that often they need to cooperate with each student individually:

$X$ is indifferent and I have to check every so often where he is at. Often, I will need to individually take him to the board and tell him "Do this". I will not wait for him to put up his hand, because if I wait, he will never do it. (R5)

I ask them all the same, but I try to help each one as much as they need; for instance, I won't ask a difficult question to $S$. I may even give the answer through the question. (R3)

As regarding the assessment of the migrant students' performance, all the teachers believed that these students face difficulties in the subject of Modern Greek Language mainly due to the lack of language motivation in their family environment:

The migrant children I have in my class are lagging behind in the Greek Language lesson in relation to the Greek students as a result of their ethnic origins. (R5)

All the teachers believed that the performance of the migrant students, whether high or low, was due more to their mental abilities, in other words to the fact that they are or are not by intelligent, or to the effort they make or do not make, rather than to their ethno-cultural origins. They support this view by the observation that the student, whether Greek or a migrant, will face problems if they do not study or if they are not 'bright'. Besides effort, others factors stated as influencing students' performance personal abilities. Teachers based these views on their own observations that while many migrant students cannot succeed at school, others from the same ethnic background are very good students, which underlines, from their point of view, that performance is mainly a matter of inheritance and personal potential rather than nationality. The teachers brought up the fact that there are cases where siblings showed great differences in school performance, which is a consequence of their different abilities:

Yet more proof that it is his [powerful] mind, A. also has a brother in the Second Grade of Gymnasium who is nothing like him. He isn't doing well [at school]. (R4)

One teacher stated the view that the performance of migrant students is more closely associated with the efforts made by the teacher to help them than to their nationality, thus in this way stressing the teacher's important role:

Generally, I do not think that the nationality of these children is related to their performance. I think it matters how you embrace 
these children and how you treat them and how you are going to help them improve. (R2)

It was also reported that the first migrant generations are more educationally "underprivileged" because of the culture shock they suffered, whereas the following generations are more informed and will have a better performance in school:

They are children of the first generation who came. Their parents came here only for work. I believe that the next generation will be much more informed. The parents experienced culture shock. They could not understand how some basic values operate because they did not have the time or the luxury. (R4)

Finally, regarding the participation of migrant students in the class, which affects their performance, teachers believe that it is influenced by the child's character and not by their ethno-cultural origin. Thus, both Greek and migrant students who are shy and timid rarely participate in the lesson, even if they are good at the subject:

A. is a weak student. Meanwhile I had a cousin of A's in my class who was a star. That is, a child from the same environment, without stimulus, etc., E. did not have the experience, but you saw, she was constantly "Miss can I ask you something?" and "Where can I find information about this [or that]?" (R1)

\section{Social Relationships between Greek and Migrant Students}

Teachers, referring to the relationships between their Greek and migrant students, stressed that they are smooth and are governed by respect for diversity. This perception was based on the observation that any reference made by the migrant students to some aspect concerning their homeland which may have seemed strange to Greek society, the native students reacted to with interest and were not condescending. They are of the opinion that in today's schools, the fact that some children have a different ethnic background is treated as something normal and not in a racist manner. It was stated that children do not pay attention to cultural diversity. In fact, the teachers observed that many of their Greek students did not realize there were different nationalities until they were told [about it]:

I believe they are able to understand it; in other words, everybody now accepts diversity. Our society has changed its beliefs. There was a case in a previous year when I had an Albanian student, who, when at the end [of the school year] he said "Now that the schools are closing, I'm going to Albania", that's when the children realized that their classmate was Albanian. They had not realized it at all. They did not care. (R4)

Let's say A. says: "In my village, we don't have electricity", we take it from there and we ask lots of questions and the children respond. They participate, ask, and express their questions to A. Because A. is and has always been one of them, what he says, they take it in the same as they would have had any other child said it. It has nothing to do with nationality, or at least there is no such issue in my class. (R1) 
The teachers believe that if a migrant student behaves well, is a good student, and has a number of different talents, then they easily create friendships with their classmates without being hampered by their different ethnic-cultural origins.

Another reason given as to why Greek and migrant students have good relationships is the fact that many of the migrant children came to Greece at an early age and have socialized with Greeks all their lives. Furthermore, the teachers believe that if migrant children have lived in Greece for many years from a very young age, they feel one with the Greek students, because they have become more familiar with the environment and so develop good relationships with the Greeks:

The most basic thing with my class is that the children have been together since kindergarten. These children have bonded and have been integrated; they feel that they are all one class. (R5)

The teachers stated that foreign students who start Greek school when they are older often face problems in integrating and developing friendships with the Greek students, because in these cases they usually stand out. However, the teachers believe that if a migrant student is social, outward going, and good at a sport, they can very easily adapt to a new environment, even if they have come to Greece at an older age.

Another observation reported by the teachers was that there are Greek students who, although they have migrant children as friends, react negatively to diversity, mainly in the areas of religion and history. At the same time, these students claim that they treat the differences concerning migrants as "simply natural differences" such as those that exist between Greek students, and cannot separate them. The teachers claim that in most cases, Greek students actually love and befriend migrant children, although they may put them down verbally without even knowing it:

He probably did not understand. From what he had heard others saying "Albanians do this and Albanians do that" he too called him Albanian as if showing that he was different [to the rest]. That is, unconsciously he saw that he was different, but because he was his friend and he loved him, he accepted him. (R1)

It was also reported that if migrant children feel accepted by their peers, they have no problem with what may be deemed to be "racist" comments against them:

Last year even his closest friends called him [the] Albanian. But N. did not react. That is, because he knew that they loved him and they were his friends he did not react, it didn't bother him. (R4)

\section{The Teacher's Pedagogical Role in Cultural Diversity}

The teachers stressed the fact that despite the different ethno-cultural origins of Greek and migrant students, all students should be treated the same, meaning that, the teacher should not discriminate between them, and more precisely, if they want to be fair towards their migrant students, they ought to treat them as they would their Greek students:

At the beginning, when A. had first come, he was afraid, he did not speak Greek, but I was very good to him. I spoke to him as I would speak to a Greek. I did not make him stand out. (R2) 
Regarding the role of the teacher in the management of relationships between Greek and migrant students, it is considered good practice to take a stand when racist comments are made by the Greeks at the expense of the migrants. It is believed that the most effective way to restore the relationships between Greek and migrant students is to defend the latter in the case of conflict or disagreement.

[Just] think last year that $N$ was being called [the] "Albanian" even by his closest friends. [...] I told his friend that what he is doing is not right and that he would not like it if he were called [the] Greek. [...] After I kept on at them, this year they have stopped doing it. But last year, all the time they kept calling him that and I did not like it. (R1)

In addition, it was stated that if the national identity of the migrant students is treated as inferior, then the teacher should intervene in favor of the child in order to protect them. It was also reported that migrants are unwilling even to attend school when they feel powerless and rejected, although the insecurity that they may sometimes feel at school is mainly attributed to their character/personality rather than to their ethno-cultural origins. In many cases these children will avoid talking about their homeland as they feel inferior, and whenever a migrant child might make such a reference, it usually happens unconsciously rather than consciously. It is thought, therefore, that in such cases the teacher has to support the migrant students, creating an atmosphere in which they will feel safe in a familiar environment.

It is argued, however, that the teacher should not give more or fewer opportunities to migrant students only because of their cultural diversity. In the case where these children were born in Greece and know Greek as if it were their mother tongue, there is no reason to treat them differently to Greek students:

\section{I have not noticed that there is a need for more specific treatment for migrant children. Because these children have been born in Greece, there is no need to treat them differently because they know our language. (R3)}

\section{Discussion and Conclusions}

It is interesting that in the study all the teachers stated that differentiation of teaching is important as it covers the needs of students who in the same class are at different levels. However, none of them spoke conclusively regarding the need for differentiated instruction in the classroom due to the different ethno-cultural backgrounds of their students. This demonstrates teachers' inability to respond to the teaching requirements of a culturally diverse class (Kordolemis, 2017; Spinthourakis \& Karakatsanis, 2011), or to perceive and acknowledge that they use an assimilative approach to teaching (Gropas \& Triandafyllidou, 2011; Kaldi et al., 2017; Karanikola, 2015; Magos, 2004; Morales et al., 2020; Palaiologou \& Faas, 2012; Sakka, 2010; Van Overschelde \& Piatt, 2020). The types of differentiation methods that the teachers in the study recommended with respect to weaker students, irrespective of nationality, consisted of: more frequent positive reinforcement through praise, more contact and cooperation during the lesson, formulating easier questions addressed to them, and generally offering assistance depending on each pupil's needs (Palaiologou \& Faas, 2012). There seems to be an ambiguity in the teachers' responses since although they consider it necessary to reward the weaker students, who more often tend to be migrants, at the same time they state that there are no particular differences between Greek and migrant students. This fact shows the need for differentiated instruction, thus, ignoring not only the influence of culture on students' education 
(Jokikokko, 2005; Kaldi et al., 2017), but also the practices that can be implemented in order to highlight and exploit the cultural characteristics of migrant students (Kesidou, 2008; Messing, 2008).

As is the case with a significant number of similar studies in Greece (Kontogianni, 2002; Ksinogala, 2000; Sakka, 2010; Spyridakis, 2002; Tsaliki, 2012), the present study's findings seem to support the conclusion that Greek teachers have an assimilative approach to education. They ignore the linguistic and cultural capital of ethnic minority students, and manage classes as if they were homogeneous rather than multiethnic, due to the fact that the majority of the migrant pupil population speaks Greek, in many cases better than their mother tongue. Although teachers seem to find it desirable that migrant students use the dominant language at school, we believe, it should be cause for concern, on the grounds that it is not in keeping with the basic principles of intercultural education or the framework of education for equal opportunities (Angelides et al., 2004; Dimitriadou \& Efstathiou, 2008; Hajisoteriou, 2012; Magos, 2004).

The fact that teachers believe that the child's ethno-cultural background has no effect on class participation and performance of migrant students, which they assert are influenced more by other factors, such as personality, abilities or interest in the subject, was of special interest. The present study's findings reveal that in many cases, teachers tend to underestimate or even deny the cultural diversity between Greek and migrant students in their class, considering that what affects their behavior and school performance is exclusively the pupil's individuality, an individuality which, however, does not seem to be influenced by a particular ethno-cultural context (Tsiga, 2011).

The main perception that teachers hold in regards to inter-student relationships is that it is in the hands of the migrant students themselves to solve issues of isolation and marginalization, since the more social and extroverted they are, and the better students they are at school, the more easily they can develop friendships with their Greek classmates. This view, however, ignores on the one hand, the general pedagogical role played by the school, and on the other, the particular dimension of the teacher's professional role that is associated with the help and guidance given to their young students in order to develop strong social ties in the classroom (Angelides et al., 2004; Hajisoteriou, 2012; Papamichael, 2008; Tatar \& Horenczyk, 2002). They thus place the burden of marginalization on the migrant students themselves, disregarding the onus of the educational and social structures which foster inequalities and injustices to the detriment of ethnic minority students (Elmeroth, 2009; Gilbert, 2004; Vareli, 2014). In comparison, the teachers reported that their Greek students maintain excellent relationships with many of their migrant classmates, without paying attention to ethno-cultural differences, due to the fact that these minority students are fully adapted, in other words assimilated into the Greek school environment. According to Garcia \& Lopez (2005), it is important for friendly ties to be developed between native and migrant students, in order to cultivate empathy and acceptance for cultural diversity in the majority group. However, from the findings of the present research, it appears that Greek students do not perceive any cultural diversity due to the almost complete assimilation of migrant students into Greek society.

The area where the views of all the primary school teachers who participated in the study converge is the importance of the migrant students' full adaptation into the fabric of the Greek school, not only for successful inter-student relationships between minority and majority groups, but for the best possible schooling for culturally diverse students. All the teachers stated that the younger the migrant children were when they arrived in Greece, the more easily and quickly they adapted to Greek society, since, on the one hand, they are then able to develop close ties with their Greek peers, and on the other, they become familiar with the Greek language, which in turn helps them to improve their school performance (Palaiologou \& Evangelou, 2011). Some of the teachers stated that their migrant students feel fully accepted by their Greek classmates and do not stand out from the rest; they feel comfortable in both the 
social and school environment. It is claimed by the teachers that these factors are adequate and necessary for the development of friendships between them and their Greek classmates, and by extension for the best possible education and performance of these students at school. The teachers' perceptions in accordance with their personal theories are, therefore, assimilationist. In a nutshell, they accept the full assimilation of their migrant students into Greek society as normal; cultural diversities between migrant and Greek students are treated as an issue which helps the migrant population better adapt to Greek society; and that respect for diversity on the part of the Greek students is not an issue, since students from migrant backgrounds have been 'Hellinized', which helps them to perform better in both their school and social progress (Gropas \& Triandafyllidou, 2011; Magos, 2004).

In respect to the pedagogical role of teachers, the participants stated that among their responsibilities was to promote the equality of students and not to differentiate between them, whether they were Greeks or migrants. The reason given for this view is that migrant students do not differ in any way from the Greeks, so there is no reason to treat them differently, a fact which reveals their inadequacy in dealing with the challenges of a multicultural class (Spinthourakis \& Karakatsanis, 2011). Having said this, however, according to the findings, when there is a conflict between Greek and migrant students, the teachers stated that it is their role to defend the minority group. This indicates that teachers perceive intercultural education only in its anti-racist dimension, but in a way that is actually "didactic" rather than experiential. They do not seem to be aware of any degree of contradiction in their personal theories and behavior. Specifically, in rewarding migrant students more, providing assistance according to the needs of each pupil, as well as reinforcing and encouraging the weakest students, which in most cases tend to be migrants. This is despite having emphasized the fact that there are no particular differences, whether educational or social, between migrant students and their Greek classmates. Paradoxically, what emerges from the teachers' reports is that while they claim that migrant students do not differ from their Greek counterparts and do not need differential treatment, their practice does not seem to be fully compatible with what they say. By implicitly or explicitly acting in "favor" of migrant students, they are in fact behaving in a positively discriminatory way in order to provide fairer, more equitable opportunities. The findings from the present study confirm that teachers hold contradictory perceptions about the management of cultural diversity in the classroom (Guo et al., 2009; McCorkle, 2020).

A possible reason for not taking the ethno-cultural capital of their migrant students into account in their teaching practice is the assumption on their part that intercultural education is a component of the curriculum only at the specific schools (Pantazi, 2008) designated by the Greek Ministry of Education as Intercultural Schools, and does not apply to the mainstream schools they work in (Palaiologou \& Faas, 2012; Sakka, 2010). Nevertheless, the lack of intercultural awareness of teachers who teach in classes with a multicultural composition is an obstacle to the emergence of cultural pluralism, with the result that teachers either ignore issues related to the management of cultural diversity within the classroom or mishandle these issues (Magos, 2007). The misconception that the principles of interculturality do not have to apply to mainstream primary and non-intercultural schools (Gropas \& Triandafyllidou, 2011), confirms the gap between government policy and educational practice. Theoretically, the equitable interaction of diverse cultures living in Greek society is encouraged; in reality, however, what seems to take place is the 'Hellinization' of immigrants (Palaiologou \& Faas, 2012; Sakka, 2010). In sum, the Greek educational system in general, and the teachers in particular, implement assimilation strategies, focusing on the dominant culture and overlooking all aspects of diversity (Sakka, 2010; Warikoo \& Carter, 2009). Such an ethno-centric approach, suggesting a homogenizing function of the Greek educational system, however, ignores linguistic and cultural coexistence and diversity (Sakka, 2010), which is very important because not only does it teach students to tolerate and respect each other's cultures and religions (Sharan, 2010), but also offers socially responsible, and equitable education. 
The study of personal theories for managing cultural diversity in the classroom illuminates invisible aspects of teaching and is a valuable guide for the teachers who want to reflect on their teaching practice. Through this procedure they will receive the necessary feedback in order to deal more effectively with difficult situations concerning cultural diversity within their class. Finally, it is very important for the empowerment of teachers in the more effective management of cultural diversity their training on intercultural principles, so that they are able to use the cultural capital of their immigrant pupils instead of marginalizing it.

Note: This pilot study was the preparatory stage for further research in the field of intercultural education in Greek primary schools, accomplished during the post-graduate studies of the second author.

\section{References}

Angelides P., Stylianou, T., \& Leigh, J. (2004). Multicultural education in Cyprus: A pot of multicultural assimilation. Intercultural Education, 15(3), 307-315.

Banks, J. (2006) Diversity and Citizenship Education: Global Perspectives. Wiley. Jossey Bass.

Beckett, G. H., \& Kobayashi, M. (2020). A Meta-study of an Ethnographic Research in a Multicultural and Multilingual Community: Negotiations, Resources, and Dilemmas. American Journal of Qualitative Research, 4(1), 85106. https://doi.org/10.29333/ajqr/8267

Bolkas, N. (2015). Immigration policies in the European Union and Greece - Integration strategies [Doctoral dissertation, University of the Aegean, Rhodes].

Bromme, R. (1980). Die alltägliche Unterrichtsvorbereitung von Mathematiklehrern. Unterrichtswissenschaft [The everyday lesson preparation of math teachers]. Teaching science, 8, 142-156.

Burkett, B. (2014). Developing a personal theory of teaching practice: The role of reflection. Korea TESOL Journal, 11(1), 19-34.

Calderhead, J. (1981). Stimulated recall: A method for research on teaching. British Journal of Educational Psychology, 51(2), 211-217.

Calderhead, J. (1996). Teachers: Beliefs and Knowledge. In D. C. Berliner \& R. C. Calfee (Ed.), Handbook of educational psychology (pp. 709-725). Lawrence Erlbaum Associates

Ciges, A. S., \& Lopez, R. G. (1998). Teacher training with a view towards developing favourable attitudes regarding intercultural education and cultural diversity. European Journal of Intercultural studies, 9(1), 63-77.

Dann, H-D. (1989). Subjektive Theorien als Basis erfolgreichen Handelns von Lehrkräften [Subjective theories as the basis for successful teacher action]. Beiträgezur Lehrerinnen- und Lehrerbildung [Contributions to teacher education], 7(2), 247-254. urn:nbn:de:0111-pedocs-131612.

Dann, H.-D. (1994). Pädagogisches verstehen: Subjektive theorien und erfolgreiches handeln von lehrkräften [Pedagogical understanding: Subjective theories and successful action by teachers]. In K. Reusser \& M. Reusser-Weyeneth (Eds.), Verstehen: Psychologischer prozess und didaktische Aufgabe [Understanding: Psychological process and didactic task] (pp. 163-181). Huber.

Dann, H.-D., Tennstädt, K.-C., Humpert, W., \& Krause, F. (1987). Subjektive Theorien und erfolgreiches Handeln von Lehrern/-innen bei Unterrichtskonflikten [Subjective Theories and successful action by teachers in the event of class conflicts]. Unterrichtswissenschaft [Teaching Science], 15, 306-320. 
Danziger, K. (2001). Introspection: History of the concept. In N. J. Smelser \& P. B. Baltes (Eds.), International encyclopedia of the social \& behavioral sciences (pp. 7889-7890). Elsevier.

Dietrich, I. (2006, October 21-23). Education and multiculturalism - changing demands to schools [Proceedings]. In D. Chatzidimou \& Vitsilaki, C. (Ed.), School in the information society and multiculturalism (pp. 45-60). IA' International Conference, Rhodes, Thessaloniki.

Dimitriadou A., \& Efstathiou, M. (2008). Teaching approaches in mixed classes. In Training Guide: Intercultural education (pp. 67-85). Thessaloniki.

Domingo, S., \& Guerrero, N. (2018). Extent of Students' Practices as Digital Citizens in the 21st century. Research in Social Sciences and Technology,3(1), 134-148. https://doi.org/10.46303/ressat.03.01.9

Elmeroth, E. (2009). Student attitudes towards diversity in Sweden. Intercultural Education, 20(4), 333-344.

Ferris, E. (2019). Lessons of Policing and Exclusion. Journal of Culture and Values in Education, 2(3), 25-43. https://doi.org/10.46303/jcve.03.02.2

Fussangel, K. (2008). Subjektive Theorien von Lehrkräften zur Kooperation. Eine Analyse der Zusammenarbeit von Lehrerinnen und Lehrern in Lerngemeinschaften [Subjective theories of teachers on cooperation. An analysis of the cooperation between teachers in Learning communities] [Doctoral dissertation, Universitat Wuppertal].

Garcia, O. M., \& Lopez, R. G. (2005). Teachers' initial training in cultural diversity in Spain: attitudes and pedagogical strategies. Intercultural Education, 16(5), 433-442.

Gibbs, B. (2020). Critical teaching in classrooms of healing: Struggles and testimonios. Journal of Curriculum Studies Research, 2(1), 95-111. https://doi.org/10.46303/jcsr.02.01.6

Gilbert, D. (2004). Racial and religious discrimination: The inexorable relationship between schools and the individual. Intercultural Education, 15(3), 253-266.

Govaris, C. (2011). Introduction to Intercultural Education. Diadrasi Editions.

Govaris, C., \& Kaldi, S. (2010). The Educational Challenge of Cultural Diversity in the International Context. Waxmann Verlag.

Groeben, N., Wahl, D., Schlee, J., \& Scheele, B. (1988). Das Forschungsprogramm SubjektiveTheorien. Eine Einfhrung in die Psychologie des reflexiven Subjekts [The Subjective Theories research program. An introduction to the psychology of the reflexive subject]. Francke.

Gropas, R., \& Triandafyllidou, A. (2011). Greek education policy and the challenge of migration: An 'intercultural' view of assimilation. Race Ethnicity \& Education, 14(3), 399-419.

Guo, Y., Arthur, N., \& Lund, D. (2009). Intercultural inquiry with pre-service teachers. Intercultural Education, 20(6), 565-577.

Gurer, C. (2019). Refugee Perspectives on Integration in Germany. American Journal of Qualitative Research, 3(2), 52-70. https://doi.org/10.29333/ajqr/6433

Hajisoteriou, C. (2012). Intercultural education set forward: Operational strategies and procedures in Cypriot classrooms. Intercultural Education, 23(2), 133-146.

Hajisoteriou, C., \& Angelides, P. (2016). Intercultural education in situ. Journal for Multicultural Education, 10(1), 33-52.

Hysa, E. (2020). Impact of Cultural Diversity on Western Balkan Countries' Performance. Journal of Ethnic and Cultural Studies, 7(1), 20-40. DOI: http://dx.doi.org/10.29333/ejecs/292

Inglis, C. (2008). Planning for cultural diversity. UNESCO.

Jokikokko, K. (2005). Interculturally trained Finnish teachers' conceptions of diversity and intercultural competence. Intercultural Education, 16(1), 69-83. 
Kaldi, S., Govaris, C., \& Filippatou, D. (2017). Teachers' views about pupil diversity in the primary school classroom. Compare: A Journal of Comparative \& International Education, 48(1), 2-20.

Karanikola, Z. (2015). The management of cultural diversity based on the international and Greek legal framework. Intercultural sensitivity and ability of primary education teachers in the Prefecture of Aitoloakarnania. [Doctoral thesis, University of Patras].

Kesidou, A. (2008). Intercultural education: an introduction. In: Training guide: Intercultural education (pp. 21-36). Thessaloniki.

Kesidou, A., \& Papadopoulou, V. (2008). The intercultural dimension in basic teacher education: Necessity and applications. Pedagogical Epitheorisi, 45, 37-55.

Kontogianni, D. (2002). Bicultural-bilingual education in Greece: the case of 'Greek repatriates 'schools' [Doctoral thesis, University of Crete].

Kordolemis, E. (2017). Educational policy and institutional provisions for the inclusion of foreign students in primary education in EU member states: The Greek case [Doctoral Thesis, National and Kapodistrian University of Athens].

Ksinogala, N. (2000). Gypsies' cultural capital as a framework of interpretation for their participation in education. The case of the 39'1 primary school in Heraklion, Crete [Master's thesis, University of Crete].

Magos, K. (2004). Training of teachers in the management of ethno-cultural differences. The case of the majority teachers in the Minority Schools of Thrace [Doctoral thesis, National and Kapodistrian University of Athens].

Magos, K. (2007). Examples of best practice: 'All together we are the city': A workshop developed by the Muslim Minority Education Project in Greece. Intercultural Education, 18(2), 161-168.

Mandl, H., \& Huber, G. L. (1983). Subjective theorien von lehrern [Subjective theories from teachers]. Psychology in Erziehung \& Unterricht [Psychology in Education \& Teaching], 30, 98-112.

Mayring, P. (2000). Qualitative content analysis. Forum: Qualitative Social Research, 1(2), Article 20.

McCorkle, W.D. (2020). The Relationship Between Teachers' Grade Level and Views on Immigration and Immigrant Students. Journal of Social Studies Education Research, 11(1), 21-41. Retrieved from https://jsser.org/index.php/jsser/article/view/1771

Messing, V. (2008). Good practices addressing school integration of Roma / Gypsy children in Hungary. Intercultural Education, 19(5), 461-473.

Morales, D., Ruggiano, C., Carter, C., Pfeifer, K., \& Green, K. (2020). Disrupting to Sustain: Teacher Preparation Through Innovative Teaching and Learning Practices. Journal of Culture and Values in Education, 3(1), 1-20. https://doi.org/10.46303/jcve.03.01.1

Nikolaou, G. (2011). Inclusion and education of foreign students in primary school. Pedio Editions.

Palaiologou, N. (2004). Intercultural education and practice in Greece. Needs for bilingual intercultural programs. Intercultural Education, 15(3), 317-29.

Palaiologou, N. (2013). The path of intercultural education in Greece during the last three decades: Reflections on educational policies and thoughts about next steps. International Journal of Education for Diversities (IJE4D), 1, Article 61.

Palaiologou, N. (2020). Rethinking intercultural education in times of migration and displacement. Cambridge Scholars Publishing.

Palaiologou, N., \& Evangelou, O. (2011). Intercultural pedagogy. Pedio.

Palaiologou, N., \& Evangelou, O. (2012). Second generation immigrant students in the Greek education system. Integration and school performance. Pedio. 
Palaiologou, N., \& Faas, D. (2012). How 'intercultural' is education in Greece? Insights from policymakers and educators. Compare: A Journal of Comparative \& International Education, 42(4), 563-584.

Palaiologou, N., Kameas, A., Prekate, V., \& Liontou, M. (2019, October 24-25). Refugee hospitality center in Athens as a case study: Good (and not-so-good) practices [Proceedings]. Conference Migrant children's integration and education in Europe: Approaches, methodologies and policies, Fundació Antoni Tàpies, Barcelona.

Palaiologou, N., Nikolaou, G., Liontou, M., \& Prekate, V. (2020). Identities and linguistic landscapes of unaccompanied refugee minors: A case study from Greece, Multicultural Education Review.

Pantazi, E. (2008). Voices from the Greek community schools: Bilingual pedagogy and teachers' theories. Innovation in Language Learning \& Teaching, 2(2), 189-205.

Papadopoulou, V. (2008). Intercultural communication in school and classroom. In Training guide: Intercultural education (pp. 53-65). Thessaloniki.

Papadopoulou, V. (2015). Teaching observation: Theoretical framework and applications. Thessaloniki.

Papamichael, E. (2008). Greek-Cypriot teachers' understandings of intercultural education in an increasingly diverse society. The Cyprus Review, 20(2), 51-78.

Rakkas, G. (2017). Multiculturalism and social cohesion: Greeks and immigrants in the neighborhood of St. Panteleimon. [Doctoral thesis, Panteion University].

Ratini, T. (2019). Refugee. American Journal of Qualitative Research, 3(2), 9799. https://doi.org/10.29333/ajqr/6432

Richardson, V. (1996). The role of attitudes and beliefs in learning to teach. In J. Sikula (Ed.), Handbook of research on teacher education (pp. 102-119). Macmillan.

Sakka, D. (2010). Greek teachers' cross-cultural awareness and their views on classroom cultural diversity. Hellenic Journal of Psychology, 7(1), 98-123.

Scheele, B., \& Groeben, N. (1998). Das Forschungsprogramm Subjektive Theorien [The Subjective Theories Research Program]. Fremdsprachen Lehren \& Lernen [Foreign Languages Teaching and Learning], 27, 12-32.

Schmidt, C. (2015). Honouring the contributions of Jim Cummins to language and intercultural education internationally. Intercultural Education, 26(6). Taylor \& Francis, Routledge.

Sharan, Y. (2010). Cooperative learning: A diversified pedagogy for diverse classrooms. Intercultural Education, 21(3), 195-203.

Skourtou, E., Kourtis-Kazoullis, V., Aravossitas, T., \& Trifonas, P. P. (Eds.). (2020). Language diversity in Greece. Local challenges with international implications. Springer Publications.

Sousa, D. (2014). Validation in qualitative research: General aspects and specificities of the descriptive phenomenological method. Qualitative Research in Psychology, 11(2), 211 227.

Spinthourakis, J. A., \& Karakatsanis, D. (2011). The multicultural class in Greece. In J. A. Spinthourakis, J. Lalor, \& Berg, W. (Eds.), Cultural diversity in the classroom. A European comparison (pp. 45-61). Germany.

Spyridakis, J. (2002). The correspondence between intercultural pedagogical theory and educational practice in the intercultural schools founded by the law 2413/1996. The case of the intercultural primary school in Sapes Rodopi [Master's dissertation, University of Crete].

Straub, J., \& Weidemann, D. (2015) Handelnde subjekte. "Subjektive theorien” als gegenstand der verstehend-erklärenden psychologie. Psychosozial.

Tarman, İ. \& Tarman, B. (2011). Developing effective multicultural practices: A case study of exploring a teacher's understanding and practices. The Journal of International Social Research, 4 (17). 573-593. 
Tatar, M., \& Horenczyk, G. (2002). Teachers' attitudes toward multiculturalism and their perceptions of the school organizational culture. British Teaching \& Teacher Education, $18(4), 435-445$.

Theodorou, A. (2012). Subjective teaching theories of primary education teachers [Doctoral thesis, University of Western Macedonia].

Theodosiadou, K., \& Papadopoulou, V. (2015, November 28-30). Teacher theories for foreign students in Greek classes [Proceedings, pp. 543-555]. The 9th Panhellenic Conference on 'Greek Pedagogical and Educational Research', Florina.

Tsaliki, E. (2012). Intercultural education in Greece the case of thirteen primary schools [Doctoral thesis, University of London].

Tsiga, E. (2011). The self-esteem of foreign elementary and middle school students in primary school and its impact on their school performance (empirical research) [Doctoral thesis, University of Ioannina].

Van Overschelde, J., \& Piatt, A. (2020). U.S. Every Student Succeeds Act: Negative Impacts on Teaching Out-of-Field. Research in Educational Policy and Management, 2(1), 122. https://doi.org/10.46303/repam.02.01.1

Vareli, E. (2014). Society and School - The new sociological framework of a multicultural school in primary education [Doctoral thesis, Panteion University].

Wahl, D. (1981). Methoden zur Erfassung handlungssteuernder Kognitionen von Lehrern, in: M. Hofer, Informationsverarbeitung und Entscheidungs -Verhalten von Lehrern. Beitrage zu einer Handlungstheorie des Unterrichts, s. 49-77. Munchen: Urban \& Schwarzenberg. Methods for recording action-controlling cognitions of teachers, in: M. Hofer, information processing and decision-making behavior of teachers. Contributions to an action theory of teaching.

Warikoo, N., Prudence (2009). Cultural explanations for racial and ethnic stratification in academic achievement: a call for a new and improved theory. Review of Educational Research 79, no. 1:366-394.

Yusoff, N. (2019). Cultural heritage, Emotion, Acculturation, Ethnic minority, Valence. Journal of Ethnic and Cultural Studies, 6(3), 53-63. DOI: http://dx.doi.org/10.29333/ejecs/259

\section{Notes on Contributors}

Dr. Vassiliki Papadopoulou is Professor of Pedagogy at the University of Western Macedonia. Her articles have been published at international and national journals.

Mrs Kyriaki Theodosiadou is English language teacher. She acquired her Master Degree from the University of Western Macedonia and currently she is a Ph.D. student.

Dr. Nektaria Palaiologou is Associate Professor of Intercultural Education at at the University of Western Macedonia (UoWM) and at the Hellenic Open University (HOU). In 2018 she was elected Vice President of the International Association for Intercultural Education (IAIE). She is also serving as Editor in Chief at the Intercultural Education Journal, Taylor and Francis, Routledge and is Editorial Board member at seven international journals. Her books have been published by international publishing companies (CSP, Routledge) and national (PEDIO, in Greece), as well as her articles. 